\title{
Ploidy level enhances the photosynthetic capacity of a tetraploid variety of Acer buergerianum Miq.
}

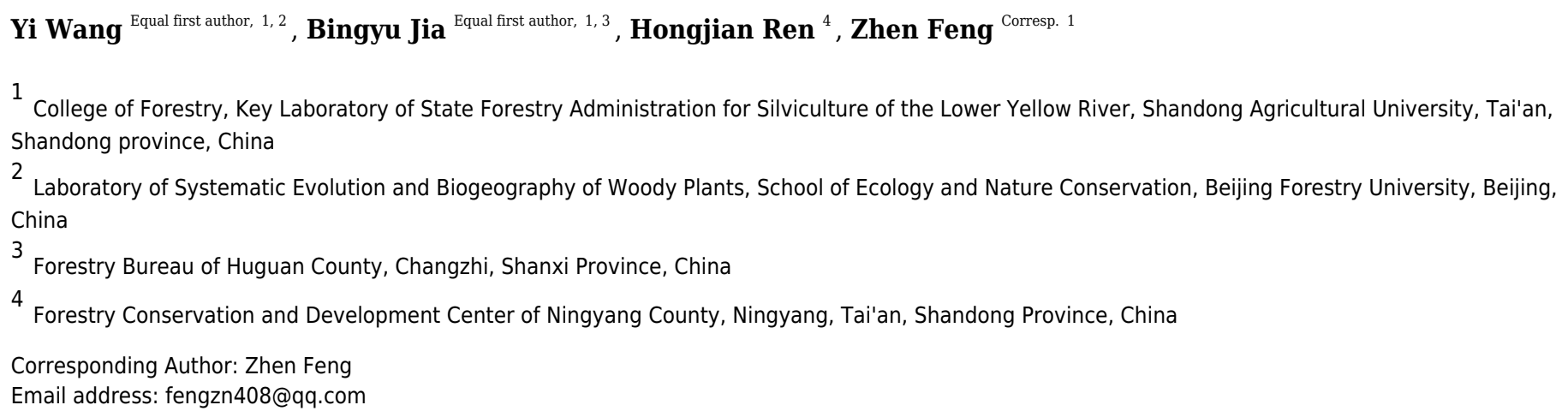

Background. Polyploidy plays an important role in plant breeding and has widespread effects on photosynthetic capacity. To determine the photosynthetic capacity of the tetraploid variety Acer buergerianum Miq. 'Xingwang', we compared the gas exchange parameters, chloroplast structure, chlorophyll contents, and chlorophyll fluorescence parameters between the tetraploid Acer buergerianum 'Xingwang' and the diploid 'S4'. To evaluate the effects of genome duplication on the photosynthetic capacity of Acer buergerianum 'Xingwang', the transcriptomes of the autotetraploid 'Xingwang' and the diploid 'S4' of $A$. buergerianum were compared.Methods. The ploidy of Acer buergerianum 'Xingwang' was identified by flow cytometry and the chromosome counting method. An LI-6800 portable photosynthesis system analyzer was used to assess the gas exchange parameters of the tetraploid variety 'Xingwang' and diploid variety 'S4' of $A$. buergerianum. We used a BioMate $3 S$ ultraviolet-visible spectrophotometer and portable modulated fluorometer to measure the chlorophyll contents and chlorophyll fluorescence parameters, respectively, of 'Xingwang' and 'S4'. Illumina high-throughput sequencing technology was used to identify the differences in the genes involved in the photosynthetic differences and determine their expression characteristics. Results. The single-cell DNA content and chromosome number of the tetraploid 'Xingwang' were twice those found in the normal diploid 'S4'. In terms of gas exchange parameters, the change in stomatal conductance, change in intercellular $\mathrm{CO}_{2}$ concentration, transpiration rate and net photosynthetic rate of 'Xingwang' were higher than those of the diploid 'S4'. The chlorophyll contents, the maximal photochemical efficiency of PSII and the potential photochemical efficiency of PSII in 'Xingwang' were higher than those of 'S4'. The chloroplasts of 'Xingwang' contained thicker thylakoid lamellae. By the use of Illumina 
sequencing technology, a total of 51807 unigenes were obtained; they had an average length of $1487 \mathrm{nt}$, and the average N50 was $2034 \mathrm{nt}$. The lengths of most of the unigenes obtained ranged from 200-300 bp, with an average value of 5262, followed by those longer than $3000 \mathrm{bp}$, with an average value of 4791 . The data revealed numerous differences in gene expression between the two transcriptomes. In total, 24221 differentially expressed genes were screened, and the percentage of differentially expressed genes was as high as 46.75\% (24224/51807), of which 10474 genes were upregulated and 13747 genes were downregulated. We analyzed the key genes in the photosynthesis pathway and the porphyrin and chlorophyll metabolism pathway; the upregulation of HemB may promote an increase in the chlorophyll contents of 'Xingwang', and the upregulation of related genes in PSII and PSI may enhance the light harvesting of 'Xingwang', increasing its light energy conversion efficiency. 
2 Ploidy level enhances the photosynthetic capacity of a 3 tetraploid variety of Acer buergerianum Miq.

4

5

6 Yi Wang ${ }^{1,2}$ Bingyu Jia ${ }^{1,3}$ Hongjian Ren ${ }^{4}$ Zhen Feng ${ }^{1}$

7 and Nature Conservation, Beijing Forestry University

${ }^{3}$ Forestry Bureau of Huguan County, Changzhi, Shanxi, China

Yi Wang and Bingyu Jia contributed equally to this work.

Corresponding Author:

Zhen Feng ${ }^{1}$

Email address: fengzn408@qq.com

\section{Abstract}

${ }^{1}$ College of Forestry, Shandong Agricultural University, Key Laboratory of State Forestry Administration for Silviculture of the Lower Yellow River, Shandong, China

${ }^{2}$ Laboratory of Systematic Evolution and Biogeography of Woody Plants, School of Ecology

${ }^{4}$ Forestry Conservation and Development Center of Ningyang County, Tai'an, Shandong, China

No. 61 Daizong Street, Shandong Agricultural University, Tai'an, Shandong, 271000, China

Background. Polyploidy plays an important role in plant breeding and has widespread effects on photosynthetic capacity. To determine the photosynthetic capacity of the tetraploid variety Acer buergerianum Miq. 'Xingwang', we compared the gas exchange parameters, chloroplast structure, chlorophyll contents, and chlorophyll fluorescence parameters between the tetraploid Acer buergerianum 'Xingwang' and the diploid 'S4'. To evaluate the effects of genome duplication on the photosynthetic capacity of Acer buergerianum 'Xingwang', the transcriptomes of the 
28

29

30

31

autotetraploid 'Xingwang' and the diploid 'S4' of A. buergerianum were compared.

Methods. The ploidy of Acer buergerianum 'Xingwang' was identified by flow cytometry and the chromosome counting method. An LI-6800 portable photosynthesis system analyzer was used to assess the gas exchange parameters of the tetraploid variety 'Xingwang' and diploid variety 'S4' of Acer buergerianum. We used a BioMate 3S ultraviolet-visible spectrophotometer and portable modulated fluorometer to measure the chlorophyll contents and chlorophyll fluorescence parameters, respectively, of 'Xingwang' and 'S4'. Illumina high-throughput sequencing technology was used to identify the differences in the genes involved in the photosynthetic differences and determine their expression characteristics.

Results. The single-cell DNA content and chromosome number of the tetraploid 'Xingwang' were twice those found in the normal diploid 'S4'. In terms of gas exchange parameters, the change in stomatal conductance, change in intercellular $\mathrm{CO}_{2}$ concentration, transpiration rate and net photosynthetic rate of 'Xingwang' were higher than those of the diploid 'S4'. The chlorophyll contents, the maximal photochemical efficiency of PSII and the potential photochemical efficiency of PSII in 'Xingwang' were higher than those of 'S4'. The chloroplasts of 'Xingwang' contained thicker thylakoid lamellae. By the use of Illumina sequencing technology, a total of 51797 unigenes were obtained; they had an average length of $1487 \mathrm{nt}$, and the average N50 was $2034 \mathrm{nt}$. The lengths of most of the unigenes obtained ranged from 200-300 bp, with a number of 5258 , followed by those longer than $3000 \mathrm{bp}$, with a number of 4791 . The data revealed numerous differences in gene expression between the two transcriptomes. In total, 24221 differentially expressed genes were screened, and the percentage of differentially expressed genes was as high as $46.76 \%$ (24221/51797), of which 10474 genes were upregulated and 13747 genes were downregulated. We analyzed the key genes in the photosynthesis pathway and the porphyrin and chlorophyll metabolism pathway; the upregulation of HemB may promote an increase in the chlorophyll contents of 'Xingwang', and the upregulation of related genes in PSII and PSI may enhance the light harvesting of 'Xingwang', increasing its light energy conversion efficiency. 
56

57

58

59

60

61

62

63

64

65

66

67

\section{Introduction}

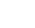

Polyploidy plays an important role in plant breeding (Otto, 2007; Dhooghe et al., 2011)

because polyploid plants often more strongly express the characteristics targeted by breedersincluding traits related to morphology, metabolism, genetic adaptation ability and tolerancethan their diploid counterparts (Comai, 2005; Leal- Bertioli, 2017). Polyploid plant growth may require more energy and carbohydrates (Evans, 2013), which are primarily obtained from the process of photosynthetic carbon assimilation in the leaves; therefore, the enhanced photosynthetic capacity of polyploids compared to diploids may be advantageous (Evans, 2013). Photosynthetic capacity is related to the chlorophyll content, the structure of chloroplasts, and related gene expression resulting from the polyploidization event. In terms of chlorophyll contents and the structure of chloroplasts, chloroplasts contain chlorophyll, which is the site of photosynthesis, so the effect of chlorophyll contents and the structure of chloroplasts on photosynthetic capacity is very obvious (Eckhardt, Grimm \& Hörtensteiner, 2004). Previous reports showed that tetraploids of $C$. nankingense had significantly higher chlorophyll a and b contents than diploids and increased photosynthetic capacity (Dong et al., 2017). In an ultrastructural study of polyploid chloroplasts and their characteristics at the transcriptome level, Chen et al. (2010) found that the number of chloroplasts, grana and lamellae in heterotetraploids of Cucumis was higher than that in diploids. Zhu et al. (2012) also found that the chloroplasts, grana and lamellae in tetraploids were present in greater numbers than in diploids during their comparison of the leaf ultrastructure of watermelon seedlings with different ploidy. In previous studies on the ultrastructure of chloroplasts, changes in the plastoglobuli in chloroplasts were ignored. The so-called plastoglobuli are also called plastid globules and lipidosomes because of their storage of fat (Wang, 2000). The plastoglobule in the chromoplast may be the product of the disintegration of the thylakoid membrane. With the disintegration of thylakoids, the number of plastoglobuli increases, and therefore, this number may be related to whether the thylakoid 
82

83

84

membrane structure is stable (Greenwood et al., 1963). The thylakoid membrane contains photosynthetic pigments and a variety of protein molecules and undergoes reactions such as those involving light energy absorption, transfer and transformation, and electron transfer; therefore, the number and structure of thylakoids are important factors that influence photosynthesis (Allen \& Forsberg, 2001; Liu, 2012). Dong et al. (2017) found that whole genome duplication enhances the photosynthetic capacity of $C$. nankingense, mainly because the number of genes associated with chlorophyll synthesis was upregulated in the tetraploid form, while those associated with chlorophyll degradation were downregulated.

The photosynthetic rate of plant cells is related to the DNA content of the cell itself; thus, the increased DNA content in polyploid mesophyll cells may endow them with a higher photosynthetic rate (Coate et al., 2012; Warner and Edwards, 1993). However, for different plants, the number of mesophyll cells per unit area changes with the increase in cell volume (Warner and Edwards, 1993); thus, at the leaf level, the effect of polyploidy on the photosynthetic capacity will vary from species to species. Therefore, in some plants, the photosynthetic rate of tetraploids is higher than that of diploids, such as Paulownia australis. (Wang et al., 2013). Studies have also shown that the photosynthetic rate of some tetraploids is lower than that of their diploid counterparts, as is the case for Fragaria (Gao et al., 2017). Acer buergerianum belongs to the Sapindaceae family, and it is native to eastern China (Hayashi, 2007) and Japan (Matsue \& Takeda, 2009). In China, Acer buergerianum is mainly distributed across the middle and lower reaches of the Yangtze River and the Taiwan region (Chinese Flora Editorial Board of the Chinese Academy of Sciences, 1981). Acer buergerianum is highly adaptable, drought-resistant, and has excellent wood. It is also an important color-leaf tree species and forest landscape resource (Feng et al., 2012; Guo et al., 2013). Therefore, vigorously developing Acer buergerianum is of great interest for improving the ecological environment and improving people's living standards. However, research on Acer buergerianum is mainly focused on landscape applications, and there is less research on its polyploid photosynthetic capacity and chloroplast ultrastructure and on the transcriptomic analysis of 
109

110

111

112

113

114

115

116

117

118

119

120

121

122

123

.

photosynthesis in this species, which limits its development. The chromosome cardinality of $A$. buergerianum is 13 , the number of diploid chromosomes is $2 \mathrm{n}=2 \mathrm{x}=26(\mathrm{Xu}, 1998)$, and the number of tetraploid chromosomes is $2 \mathrm{n}=4 \mathrm{x}=52(\mathrm{Xu}, 1998)$. Acer buergerianum 'Xingwang' is a tetraploid and is propagated by grafting. In our previous research, the tetraploid 'Xingwang' showed a significant advantage over diploid plants in terms of vegetative growth, including leaf length, leaf width, and leaf thickness (An et al., 2018). Since the increased carbohydrate accumulation required for enhanced vegetative growth is closely associated with more effective photosynthesis (Warner and Edwards, 1993), vegetative growth superiority might indicate improved photosynthetic performance in the tetraploid Acer buergerianum.

To reveal the photosynthetic capacity of the tetraploid Acer buergerianum 'Xingwang', we compared the differences between the gas exchange parameters, chlorophyll contents, chlorophyll fluorescence parameters and chloroplast ultrastructure of the diploid 'S4' and the autotetraploid Xingwang'. Additionally, comparisons between the transcriptomes of the autotetraploid 'Xingwang' and its diploid relative regarding photosynthesis were performed using Illumina high-throughput sequencing technology. This study lays a foundation for an indepth understanding of the tetraploid variety A. buergerianum 'Xingwang' and the genetic engineering of this species.

(1)

西

\section{Materials \& Methods}

\section{Plant materials}

The autotetraploid 'Xingwang' (X) originated from the colchicine-induced somatic chromosome doubling of the diploid 'S4' (S), and twenty clones with genetic consistency were obtained by grafting propagation. Young leaves of six-year-old 'Xingwang' and autodiploid 'S4' were used as 
136

137

138

139

140

141

142

143

144

145

146

147

148

149

150

151

152

153

154

155

156

157

158

159

160

161

162

experimental materials. All the test materials were obtained from the gardens of Shandong Agricultural University Forestry College (N36 $10^{\prime} 12.44^{\prime}$, , E117 $\left.09^{\prime} 40.33^{\prime \prime}\right)$ and were grown outdoors. The region has a temperate monsoon climate with an average annual temperature of $13^{\circ} \mathrm{C}$, average annual precipitation of $688.3 \mathrm{~mm}$, and annual average relative humidity of $66 \%$. The soil is loamy.

\section{Polyploidy identification}

The single-cell DNA content of the polyploid X was determined by flow cytometry (Handyem HPC-150, Canada) (Zhang, Guo \& Deng, 2006). Normal leaves of X and S were collected; the leaves were washed, and the veins were removed. Then, $20 \mathrm{mg}$ of the remaining leaf tissue was placed in a culture dish, and fresh lysis solution was added. A double-sided blade was used to chop the leaf tissue quickly in a Petri dish, and the tissue was processed for 3-5 min. A pipette was used to extract $1 \mathrm{ml}$ of the chopped sample, which was filtered into a $1.5 \mathrm{ml}$ centrifuge tube with a 300-mesh nylon sieve. Then, $1 \mathrm{mg} / \mathrm{ml}$ propidium iodide solution was added to the centrifuge tube to reach a final propidium iodide concentration of $0.1 \mathrm{mg} / \mathrm{ml}$, and the solution was allowed to stand for $5 \mathrm{~min}$. The processed solution was filtered through a 300-mesh nylon sieve again into a new centrifuge tube and then tested on the machine. Three replicates were employed for each test sample from the same plant, and at least 9000 cells were collected each time. The lysate formulation was $0.1 \mathrm{~mol} / 1$ citric acid, $0.5 \%$ TWEEN-20, $0.4 \mathrm{~mol} / 1$ disodium hydrogen phosphate, and 1\% PVP-10 (Kron \& Husband, 2012).

Chromosome ploidy identification of the polyploid X was performed using the chromosome counting method (Zhang et al., 2005). The innermost $0.5 \mathrm{~cm}$ length of the stem tip was selected as the experimental material, which was treated at $-20^{\circ} \mathrm{C}$ for $18 \mathrm{~h}$ in a stable solution (anhydrous ethanol:glacial acetic acid:trichloromethane $=5: 3: 2)$ and then stored in $75 \%$ alcohol at $4^{\circ} \mathrm{C}$. The material was removed and washed 3 times in ultrapure water. The excess water was absorbed with clean filter paper and the sample was transferred to $0.075 \mathrm{~mol} / 1 \mathrm{KCl}$ solution to reach 
163

164

165

166

167

168

169

170

171

172

173

174

175

176

177

180

181

182

183

184

185

186

187

188

189

hypotonicity for $30 \mathrm{~min}$. Following dissociation, the material was rinsed with ultrapure water 3 times and placed in ultrapure water for $30 \mathrm{~min}$ to become hypotonic. The water and Carbo Fuchsin dye (Solarbio, China) solution were then absorbed for 15-20 min, the material was pressed into a tablet, and 10-20 relatively clear metaphase cells were found under the microscope for identification.

\section{Gas exchange parameters}

The experimental site is in the garden of Shandong Agricultural University Forestry College (the environmental conditions are the same as those detailed above). We chose a sunny day in the middle of each month from May to September 2019 and selected tetraploid X and diploid S plants of equal size. We used an LI-6800 portable photosynthesis system (LI-COR, USA) to measure the net photosynthetic rate $\left(P_{\mathrm{n}}\right)$, stomatal conductance $\left(G_{\mathrm{s}}\right)$, transpiration rate $\left(T_{\mathrm{r}}\right)$, and intercellular carbon dioxide concentration $\left(C_{\mathrm{i}}\right)$ of the third pair of sun-exposed, physiologically mature leaves from the top of the side branch to the trunk at the same orientation from 3 plants, with 3 leaves collected from each plant. The gas exchange parameter data were recorded every two hours from 8:00 to 18:00, and the average value was used for the processing analysis.

\section{Determination of chlorophyll contents and chlorophyll fluorescence parameters}

Fresh leaves from diploid and tetraploid plants were cut into pieces and submerged in $80 \%(\mathrm{v} / \mathrm{v})$ acetone in the dark at room temperature to extract their chlorophyll (Arnon, 1949). The chlorophyll a (Chl a), chlorophyll b (Chl b) and total chlorophyll $(\mathrm{a}+\mathrm{b})$ contents were measured using a BioMate 3S ultraviolet-visible spectrophotometer (Thermo Fisher Scientific Inc., USA) at 470, 649, and $665 \mathrm{~nm}$ according to the methods of $\mathrm{Li} \mathrm{(2000).}$

The chloroplast fluorescence parameters of the $\mathrm{X}$ and $\mathrm{S}$ leaves were measured under slightly excessive light stress. The control group was exposed to a natural light intensity (88000 lx) while 
190

191

192

193

194

195

196

197

198

199

200

201

202

203

204

205

206

207

208

209

210

211

212

213

214

215

216

the experimental group was exposed to a $20 \%$ increased light intensity (105600 lx). The

chlorophyll fluorescence parameters were measured using a portable modulated fluorometer (PAM-2500, Heinz Walz, Germany). The maximal fluorescence $\left(F_{\mathrm{m}}\right)$ and the minimal fluorescence $\left(F_{\mathrm{o}}\right)$ were recorded. The maximal photochemical efficiency of PSII $\left(F_{\mathrm{v}} / F_{\mathrm{m}}\right)$ and the potential photochemical efficiency of PSII $\left(F_{\mathrm{v}} / F_{\mathrm{o}}\right)$ were calculated as $F_{\mathrm{v}} / F_{\mathrm{m}}=\left(F_{\mathrm{m}}-F_{\mathrm{o}}\right) / F_{\mathrm{m}}$ and $F_{\mathrm{v}} / F_{\mathrm{o}}=\left(F_{\mathrm{m}}-F_{\mathrm{o}}\right) / F_{\mathrm{o}}($ Kramer et al., 2004).

Nine samples from three individuals of each ploidy type were measured.

\section{Electron microscope sample preparation of leaf chloroplasts}

The mature leaves on the annual sun-exposed branches were collected at $4^{\circ} \mathrm{C}$, and the container and instruments were precooled. Fresh leaf samples $(1 \mathrm{~mm} \times 1 \mathrm{~mm})$ were cut from the middle part of the leaves along the main vein, fixed in $2.5 \%$ glutaraldehyde fixative solution, and stored at $4^{\circ} \mathrm{C}$. The fixed leaves were washed 3 times with $0.1 \mathrm{~mol} / 1$ phosphate buffer solution containing $1 \%$ osmium acid (Pelco, EM level, USA) at $4^{\circ} \mathrm{C}$ for $3 \mathrm{~h}$, washed 3 times with buffer solution, and then dehydrated step by step with ethanol and propylene oxide. A replacement was performed; then, the embedding material was impregnated with Spurr resin (Spi-Chem, USA). Last, the samples were polymerized in an oven at $70^{\circ} \mathrm{C}$. The embedding blocks of the different materials were placed on an ultrathin microtome (Leica EM UC6, Germany) for sectioning. The thickness of the ultrathin sections was $70 \mathrm{~nm}$. The sections were stained with uranyl acetate (Spi-Chem, ACS level, USA) and lead citrate trihydrate (Spi-Chem, ACS level, USA) and observed and photographed under a transmission electron microscope (JEM1230, JEOL, Japan). Image-Pro Plus 6.0 (Media Cybernetics, Inc. USA) was used to produce statistics on the thylakoid lamella thickness. Three samples of X and S were analyzed, and for each sample, the thylakoid lamella thickness and number of plastoglobules from at least three chloroplasts were detected.

\section{RNA extraction, library construction and RNA-seq}


218 During the transcriptome sequencing process, for $\mathrm{X}$ and $\mathrm{S}$, three biological replicates were taken 219 from the same plant, and they were denoted X1, X2, and X3 and S1, S2, and S3. Tender leaves 220 from the annual sunny branches were obtained, and an Adelaide Biologicals EASYspin Plant

221

222

223

RNA Quick Extraction Kit was used to extract the total RNA from each X and S sample. A spectrophotometer (Thermo Fisher Scientific, Inc., USA) was used for RNA quality inspection, and the integrity of the RNA was confirmed by $1 \%$ agarose gel electrophoresis.

Oligo (dT) magnetic beads were used to enrich the mRNA with a polyA tail, and interrupting buffer was used to fragment the resulting RNA. Random N6 primers were used for reverse transcription, and two strands of cDNA were synthesized to form double-stranded DNA. The ends of synthetic double-stranded DNA were filled in, and the $5^{\prime}$ end was phosphorylated. The 3' end forms a sticky end that protrudes with a base 'A'; then, there is a complementary end with a protruding base ' $\mathrm{T}$ ' on the 5 ' end, and the ligated product was amplified by PCR with specific primers. The PCR products were thermally denatured into single-stranded DNA, and then the single-stranded DNA was circularized with a bridge primer to obtain a single-stranded circular DNA library. Finally, the BGISEQ-500 platform was used to obtain raw sequencing data.

\section{De novo assembly and functional annotation}

The software SOAPnuke (Cock et al., 2010) was used to filter the raw data for sequencing, and the filtered data were called clean reads and saved in FASTQ format. Trinity software (Grabherr et al., 2011) was used to assemble then process clean reads in turn. Trinity has three independent modules: Inchworm, Chrysalis and Butterfly. The data were first assembled with Inchworm to obtain the full-length isoform transcript data and the fragment form of the isoform-containing transcript. Next, in the Chrysalis module, the contigs that may have variable splicing and parallel genes are clustered to construct a large number of individual de Bruijn maps. Last, the linear path is merged with continuous nodes in the de Bruijn maps in the Butterfly module and full-length 
244 transcript splicing subtypes are extracted.

245 Then, TGICL software (Pertea et al., 2003) was used to cluster the transcripts to remove

246 redundancies and obtain the unigenes. After clustering, the unigenes were divided into two

247 classes: clusters with the prefix CL and singletons with the prefix Unigene.

248 For the resulting transcript data, we used Trinity to perform open reading frame (ORF)

249 predictions, and we annotated the transcript with complete ORFs. After assembling the unigenes,

250 we performed bioinformatics analysis and aligned the predicted protein sequences to six

251 functional databases, namely, NCBI nonredundant protein (Nr), NCBI nucleotide in sequences

252 (NT), Swiss-Prot, Pfam, Kyoto Encyclopedia of Genes and Genomes (KEGG), euKaryotic

253 Orthologous Groups (KOG), and Gene Ontology (GO), for annotation and classification. The

254 best alignment results were used to annotate the transcriptome sequences and to determine the

255 orientation of the sequences. The All-unigene results aligmented to the NR database were

256 annotated to the GO database via Blast2GO software (Conesa et al., 2005), and the metabolic

257 pathways were compared with the KEGG database (Kanehisa et al., 2008).

258

259

Differential gene analysis

260

261

262

263

264

265

266

The DEGseq method (Wang et al., 2010) was used to detect differentially expressed genes (DEGs), calculate the P-values (P-value, hypothesis test probability) and correct the P-values to Q-values. To improve the accuracy of the DEGs, we implemented the fold change as more than twice (fold change $\geq 2.00$ ) and the Q-values (adjusted P-value) $\leq 0.05$ to screen differential genes and detect the DEGs based on the principle of a negative binomial distribution. The DEGs related to photosynthetic characteristics were selected for analysis.

Real-time quantitative RT-PCR (qRT-PCR) verification

269

270

To confirm the reliability of the sequencing analysis, the expression of the candidate genes was 
271

272

273

274

275

276

277

278

279

280

281

282

283

284

285

286

287

288

289

290

291

292

293

294

295

296

297

measured by qRT-PCR. First, ABM's 5X All-In-One RT MasterMix Kit (with the AccuRT Genomic DNA Removal Kit) was used to reverse transcribe the RNA into the first strand of cDNA, and the product was stored at $-20^{\circ} \mathrm{C}$. Nine candidate genes were selected, the sequences of the target genes were obtained from the transcriptome results (Table S1), and primers were designed. TUB was used as the internal reference gene, and a Bio-Rad CFX96TM Real-Time PCR instrument was used to complete the qRT-PCR. The reaction procedure was as follows: $95^{\circ} \mathrm{C}$ for $30 \mathrm{~s} ; 39$ cycles of $95^{\circ} \mathrm{C}$ for $5 \mathrm{~s}$ and $60^{\circ} \mathrm{C}$ for $30 \mathrm{~s}$; and then $95^{\circ} \mathrm{C}$ for $10 \mathrm{~s}$. The qRTPCR results were calculated using the $2^{-\Delta \Delta t}$ method, and whether the expression trend of the transcriptome results was consistent with the verification results was assessed. The sequences of the primers used are shown in Table S2.

\section{Statistical analysis}

Descriptive statistical analyses were used for the measured parameters to obtain the means and standard errors (SEs). One-way analysis of variance (ANOVA) was used to analyze the significance of the differences in the gas exchange parameters, chlorophyll contents, chlorophyll fluorescence parameters and chloroplast ultrastructure between $\mathrm{X}$ and $\mathrm{S}$, with the ploidy level as a fixed factor. The significance level was set at $p<0.05$. Statistical analyses were performed with SPSS 16.0 (SPSS, Inc., Chicago, IL, USA).

\section{Results}

\section{Identification of the $A$. buergerianum tetraploid}

By observing the stem tip under the microscope, we found that the chromosome number of $\mathrm{X}$ was significantly higher than that of S by twofold (Fig. S1).

The DNA content in a single cell was detected by flow cytometry, and the results are shown in 
298

299

300

301

302

303

304

305

306

307

308

309

310

311

312

313

314

315

316

317

318

319

320

321

322

323

324

Fig. S2. The ploidy level of the plant can be inferred from the peak figure of its relative DNA content (Dole el, Greilhuber \& Suda, 2007; Paul \& Husband, 2012). The main peak single-cell DNA content in the S leaves was at channel 100, while the main peak single-cell DNA content in X leaves was at channel 200. Thus, the single-cell DNA content of X was twice that of S; therefore, X was determined to be tetraploid.

\section{Gas exchange parameters, chlorophyll contents and chlorophyll fluorescence parameters}

Similar patterns of diurnal changes in $T_{\mathrm{r}}$ were observed between diploid and tetraploid $A$. buergerianum X and S leaves from May to September (Fig. S3). In May, July, and September, a single-peak curve was observed that first increased and then decreased, reaching a maximum at approximately 12:00. The peak $T_{\mathrm{r}}$ of $\mathrm{X}$ was higher than that of $\mathrm{S}$, the $T_{\mathrm{r}}$ reached the maximum in July, the maximum $T_{\mathrm{r}}$ of X was $1.33 \mathrm{~mol} \cdot \mathrm{m}^{-2} \cdot \mathrm{s}^{-1}$, and the maximum $T_{\mathrm{r}}$ of S was $1.23 \mathrm{~mol} \cdot \mathrm{m}^{-2} \cdot \mathrm{s}^{-1}$. In June and August, the daily variation of the whole day showed a double-peak curve, with the first peak appearing at approximately 10:00 and the second peak appearing at 14:00. In X and S, the first peak was greater than the second peak and fell into a valley at approximately 12:00.

The daily variation trends in the $P_{\mathrm{n}}$ of $\mathrm{X}$ and $\mathrm{S}$ leaves from May to September were similar (Fig. S4). In May, July, and September, a single-peak curve first increased and then decreased. Starting at 8:00, the Pn gradually increased, reached a maximum at approximately 12:00, and then gradually decreased; the $P_{\mathrm{n}}$ reached its maximum in August. The peak $P_{\mathrm{n}}$ of $\mathrm{X}$ was higher than that of S. The maximum $P_{\mathrm{n}}$ of X was $11.15 \mu \mathrm{mol} \cdot \mathrm{m}^{-2} \cdot \mathrm{s}^{-1}$, and the average $P_{\mathrm{n}}$ was 6.63 $\mu \mathrm{mol} \cdot \mathrm{m}^{-2} \cdot \mathrm{s}^{-1}$. The maximum $P_{\mathrm{n}}$ of S was $8.56 \mu \mathrm{mol} \cdot \mathrm{m}^{-2} \cdot \mathrm{s}^{-1}$, and the average $P_{\mathrm{n}}$ was 5.72 $\mu \mathrm{mol} \cdot \mathrm{m}^{-2} \cdot \mathrm{s}^{-1}$. The diurnal changes in June and August showed a double-peaked curve. The first peak appeared at approximately 10:00, and the second peak appeared at 14:00. The first peaks of $\mathrm{X}$ and $\mathrm{S}$ were both higher than the second peak, and the values fell into a valley at approximately 12:00. Over the five months from May to September, the maximum $P_{\mathrm{n}}$ of X increased by $4.31 \%$, 
325

326

327

328

329

330

331

332

333

334

335

336

337

338

339

340

341

342

343

344

345

346

347

348

349

350

351

352

353

354

355

$12.35 \%, 8.48 \%, 30.31 \%$, and $7.76 \%$ over $\mathrm{S}$.

The diurnal variation in $G_{\mathrm{s}}$ of $\mathrm{X}$ and $\mathrm{S}$ leaves from May to September was similar, and the $G_{\mathrm{s}}$ of X during different months was higher than that of S (Fig. S5). X and S showed a single-peak curve that first increased and then decreased in May, July, and September and was lower at 8:00 and 18:00. Starting from 8:00, $G_{\mathrm{s}}$ gradually increased and reached a maximum at approximately 12:00. The diurnal changes in June and August showed a bimodal curve. The peak $G_{\mathrm{s}}$ of $\mathrm{X}$ was higher than that of $\mathrm{S}$, and the $G_{\mathrm{S}}$ of $\mathrm{X}$ and $\mathrm{S}$ reached their maximum levels in August. In June, the first peaks of $X$ and $S$ both appeared at approximately 10:00, and the second peak appeared at 14:00. The first peaks of $X$ and $S$ both appeared at approximately 10:00 in August, and the second peaks appeared at approximately 14:00 for $\mathrm{X}$ and at approximately 16:00 for $\mathrm{S}$. The first peaks of $\mathrm{X}$ and $\mathrm{S}$ were both larger than the second peaks, and their values fell into a valley at approximately 12:00.

From May to September, the daily change curve in $C_{\mathrm{i}}$ between $\mathrm{X}$ and $\mathrm{S}$ cells presented a single valley change (Fig. S6). The diurnal variation curves of $\mathrm{X}$ and $\mathrm{S}$ both first decreased and then increased, and the $C_{\mathrm{i}}$ of $\mathrm{X}$ was greater than that of $\mathrm{S}$ during different months. Starting from 8:00, as the environmental conditions changed, the $C_{\mathrm{i}}$ gradually decreased, and the lowest value appeared at approximately 12:00 and then gradually increased.

Among the gas exchange parameters of tetraploid $\mathrm{X}$ and diploid $\mathrm{S}, T_{\mathrm{r}}, P_{\mathrm{n}}, G_{\mathrm{s}}$ and $C_{\mathrm{i}}$ all exhibited extremely significant differences $(\mathrm{P}<0.01)$. From May to September, the maximum values of all the gas exchange parameters of $X$ were higher than those of $S$ (Table 1).

The analysis of chlorophyll contents showed that the $\mathrm{Chl}$ a, Chl b and total chlorophyll contents were significantly higher in $\mathrm{X}$ than in $\mathrm{S}$ (Fig. 1A). The total chlorophyll contents of $\mathrm{X}$ and $\mathrm{S}$ were $2.47 \mathrm{mg} \cdot \mathrm{g}^{-1}$ and $1.52 \mathrm{mg} \cdot \mathrm{g}^{-1}$, respectively. The leaves of X contained $38.66 \%$ more chlorophyll than those of S. Under slightly excessive light stress, $F_{\mathrm{v}} / F_{\mathrm{m}}$ was 0.77 and 0.83 and $F_{\mathrm{v}} / F_{\mathrm{o}}$ was 3.45 and 4.95 in $\mathrm{S}$ and $\mathrm{X}$, respectively, and these values were significantly different (Fig. 1B).

\section{Ultrastructure of the chloroplast}

The ultrastructures of $\mathrm{X}$ and $\mathrm{S}$ mesophyll cell chloroplasts were further compared using a transmission electron microscope (Fig. 2). The chloroplasts of X and S were well developed, 
356

357

358

359

360

361

362

363

364

365

366

367

368

369

370

371

372

373

374

375

376

377

378

379

380

381

382

383

384

with obvious thylakoids and stacked basal particles. However, differences were observed in the internal structure of the chloroplasts from the two varieties. Compared with the chloroplasts in S, the chloroplasts in X contained thylakoid lamellae that were twice as thick (Fig. 2, Fig. 3A). In addition, the thylakoid lamellae of $\mathrm{X}$ were arranged more closely than those of $\mathrm{S}$, and more starch grains were observed in S. In the chloroplasts of the tetraploid $\mathrm{X}$, the number of plastoglobules was lower than that of the diploid S (Fig. 3B).

\section{Transcriptome sequencing and assembly}

The transcriptomes of $\mathrm{X}$ and S produced 42,804,595 nt and 44,971,637 nt raw data, respectively, and the Q20 percentages were both over 97\%.

The unigenes in each sample were clustered to eliminate redundancy, and 51797 unigenes were obtained, with an average length of 1487 nt; the average N50 was 2034 nt.

\section{Transcript database annotation}

A total of 44665 unigenes were annotated and accounted for $86.23 \%$ of all the unigenes. The numbers of unigenes annotated in the NR, NT, SwissProt, KEGG, KOG, Pfam, and GO functional databases were 43076, 36463, 32865, 34715, 34085, 34599, and 26781, respectively (Table S3), (Fig. S7).

\section{Analysis of DEGs}

A total of 24221 DEGs (Table S4) were screened between the Acer buergerianum diploid and tetraploid transcriptomes, and they included 10474 upregulated genes and 13747 downregulated genes. To study the function of DEGs related to photosynthetic characteristics in diploid and tetraploid plants, GO (Table S5) and KEGG (Table S6) classifications were determined.

We analyzed the pathways of porphyrin and chlorophyll metabolism and photosynthesis.

During chlorophyll synthesis in A. buergerianum, 5 genes encoding HemB were identified, all of 
385

386

387

388

389

390

391

392

393

394

395

396

397

398

399

400

401

402

403

404

405

406

407

408

409

410

411

which were upregulated. One gene encoded $\mathrm{HemC}$, and its expression was downregulated. One gene encoded HemE, and its expression was downregulated. Three genes encoded CHLH/D/I; 1 was upregulated, while 2 were downregulated (Fig. S8, Table 2) (Matsumoto et al, 2004; Beale, 2005).

In this study, $58 \mathrm{DEGs}$ were annotated as being related to the photosynthesis pathway, with 30 upregulated genes and 28 downregulated genes. Twelve were photosystem I (PSI)-related genes, of which the PsaA-, PsaB-, and PsaK-related genes were upregulated and the PsaG- and PsaH-related genes were downregulated; 28 were photosystem II (PSII)-related genes, of which the PsbE- and Psb27-related genes were upregulated and the PsbH-, PsbQ-, and PsbS-related genes were downregulated; 4 were cytochrome b6/f complex-related genes, of which the PetBand PetC-related genes were downregulated; 10 were photosynthetic electron transport-related genes, of which the PetH-related genes were downregulated; 8 were F-type ATPase-related genes, among which the beta-, delta-, and b-related genes were upregulated (Fig. 4) (Yamori \& Shikanai, 2016).

\section{qRT-PCR validation of the candidate DEGs}

To verify the reliability of the transcriptome sequencing results, qRT-PCR validation was performed on 9 randomly selected candidate genes (Table S1), including four upregulated genes (CL6641.Contig2_All, CL2285.Contig2_All, CL3396.Contig3_All, and CL335.Contig5_All) and five downregulated genes (CL7423.Contig2_All, Unigene5873_All, CL1401.Contig2_All, CL6251.Contig1_All, and CL5835.Contig1_All). The results were consistent with the expression patterns of the transcriptome sequencing results (Fig. S9), validating the transcriptome sequencing results obtained in this study.

Discussion 
412

413

414

415

416

417

418

419

420

421

422

423

424

425

426

427

428

429

430

431

432

433

434

435

436

437

438

A comparison of the gas exchange parameters for $\mathrm{X}$ and $\mathrm{S}$ showed that $\mathrm{X}$ plants had a higher $P_{\mathrm{n}}, T_{\mathrm{r}}, G_{\mathrm{s}}$, and $C_{\mathrm{i}}$ than $\mathrm{S}$ plants, which indicates that the gas exchange parameters of the tetraploid form of $\mathrm{X}$ were markedly higher those that of the diploid form of $\mathrm{S}$. The $P_{\mathrm{n}}$ of $\mathrm{X}$ and $\mathrm{S}$ their maximum levels in August, which may be due to favorable conditions for the growth of $A$. buergerianum such as the photoperiod and light intensity, temperature, and relative humidity (Wang et al., 2006). Among the gas exchange parameters for $\mathrm{X}$ and $\mathrm{S}$ photosynthesis, the daily variation curves in the $P_{\mathrm{n}}$ and $G_{\mathrm{s}}$ show different changes during different months. The $G_{\mathrm{s}}$ and $C_{\mathrm{i}}$ of tetraploid $\mathrm{X}$ were higher than those of $\mathrm{S}$, so the $P_{\mathrm{n}}$ differences between $\mathrm{X}$ and $\mathrm{S}$ may come from stomatal factors. The increase in the stomatal conductance of $\mathrm{X}$ is conducive to the continuous replenishment of $\mathrm{CO}_{2}$ in the intercellular space during photosynthesis, thus maintaining a high intercellular $\mathrm{CO}_{2}$ concentration and lower stomatal limitation (Du et al., 2011); as a result, the $P_{\mathrm{n}}$ of $\mathrm{X}$ was significantly higher than that of $\mathrm{S}$. This result was consistent with a previous study showing that stomata from $\mathrm{X}$ were significantly larger than those from $\mathrm{S}$ (An et al., 2018).

Chloroplasts are the main location for photosynthesis in plants, and their structure directly affects the photosynthesis and characteristics of leaves (Liu, 2012). Chen et al. (2010) used diploid melon, allogeneic triploid and allogeneic tetraploid plants as test materials to compare the differences in chloroplast ultrastructure, and the results showed that the number of chloroplasts, basal grains and lamellae increased significantly in the allotetraploids compared to the diploids. However, many previous studies have ignored the changes in thylakoids. In this study, there were more and thicker thylakoid lamellae in $\mathrm{X}$ than in S, and the arrangement of thylakoids was more densely stacked in the basal granule, which indicated that their daylighting mechanism was more effective at absorbing and converting light energy (Li, 2018). In addition, the number of plastoglobules in $\mathrm{X}$ was lower than that in $\mathrm{S}$, which may indicate that the thylakoid membrane structure of $\mathrm{X}$ was relatively stable. These differences may be one of the factors that cause the photosynthetic rate of the tetraploid $\mathrm{X}$ to be higher than that of the diploid $\mathrm{S}$.

Chlorophyll is the key photosynthetic pigment in higher plants (Masuda and Fujita, 2008). 
439

440

441

442

443

444

445

446

447

448

449

450

451

452

453

454

455

456

457

458

459

460

461

462

463

464

465

466

467

When plants are deficient in chlorophyll, abnormal thylakoid structure development often occurs (Falbel \& Staehelin, 2008). The synthesis and degradation of chlorophyll affect the development of chloroplasts and further affect the photosynthesis of plants (Eckhardt, Grimm \& Hörtensteiner, 2004). Here, the chlorophyll content of $X$ was significantly increased compared with that of $S$, which was also an important factor that made the photosynthetic capacity of $\mathrm{X}$ significantly stronger than that of $\mathrm{S}$.

The increase in chlorophyll content in X was presumably associated with the upregulation of the chlorophyll synthesis genes HemB caused by whole genome duplication. Green plants need to complete 16 steps to synthesize chlorophyll; the synthesis of chlorophyll b involves four processes, 5-aminolevulinic acid (ALA) synthesis, protoporphyrin synthesis, the conversion of protoporphyrin to protochlorophyll, and the conversion of protochlorophyll to chlorophyll a and b (Fig. S8) (Ohmiya et al., 2014). Here, among the genes involved in chlorophyll synthesis, HemB in $\mathrm{X}$ underwent major changes, and all five genes involved in HemB were upregulated. The expression of HemB (which encodes aminolevulinate dehydratase, ALAD) has a positive regulatory effect on chlorophyll biosynthesis (Tang et al., 2012); therefore, the upregulation of the gene encoding HemB may result in increased chlorophyll synthesis, thereby promoting the photosynthesis of tetraploids. This finding is consistent with the significantly higher chlorophyll contents in X than in $\mathrm{S}$.

Research has shown that the genes encoding the components of PS II and PS I are associated with dosage sensitivity (Coate et al., 2014). In many cases, gene dose sensitivity correlates with gene duplication, as described by the gene balance theory (Edger \& Pires, 2009). During photosynthesis, psaA and $p s a B$ are mainly related to light harvesting (Chitnis, 1996); thus, the upregulation of their related genes may enhance the light harvesting of X. In addition, the differential expression of the related genes in PS II may promote the efficiency of solar energy conversion into chemical energy. This hypothesis was confirmed by measurements of the $\mathrm{X}$ and $\mathrm{S}$ fluorescence parameters. Under mild light stress, the $F_{\mathrm{v}} / F_{\mathrm{o}}$ and $F_{\mathrm{v}} / F_{\mathrm{m}}$ of $\mathrm{X}$ were significantly higher than those of $\mathrm{S}$, indicating that the autotetraploid had higher light harvesting and conversion efficiency than its diploid (Liang et al., 2004). The chloroplast ATPase on the thylakoid membrane is responsible for catalyzing light-driven ATP synthesis and providing 
468 energy for carbon fixation in photosynthesis (Zhang et al., 2018); therefore, the upregulation of 469 related genes in ATPase may provide more energy for carbon fixation in photosynthesis, thereby 470 increasing the photosynthetic efficiency of polyploid $X$ and meeting its growth needs. Finally, 471 we present a schematic diagram for the possible mechanisms to show the reasons for the 472 increased photosynthetic capacity of X (Fig. 5).

473

\section{Conclusions}

In this study, ploidy identification of the variety Acer buergerianum 'Xingwang' confirmed that it is a tetraploid. The gas exchange parameters, chlorophyll contents, $F_{\mathrm{v}} / F_{\mathrm{o}}$ and $F_{\mathrm{v}} / F_{\mathrm{m}}$ of the tetraploid 'Xingwang' were significantly higher than those of the diploid 'S4'. Moreover, 'Xingwang' has a thicker thylakoid lamella and fewer plastoglobules than 'S4'. These reasons cause 'Xingwang' to have a higher photosynthetic capacity than 'S4'. The transcriptomes of the autotetraploid 'Xingwang' and diploid 'S4' were compared. We analyzed the key genes of the photosynthesis pathway and the porphyrin and chlorophyll metabolism pathway, and the upregulation of HemB may promote the increased chlorophyll contents of 'Xingwang'. The upregulation of the related genes whose products encode components of PSII and PSI may enhance the light harvesting of 'Xingwang', increasing its light energy conversion efficiency.

\section{Acknowledgments}

We thank Fenfen Si of Shandong Agricultural University for assistance with the experimental methods. 
495

496

497

498

499

500

501

502

503

504

505

506

507

508

509

510

511

512

513

514

515

516

517

518

519

An K, Feng Z, Qiao Q, Ren HJ. 2018. Identification of Natural Tetraploid Variant in Acer.

Buergerianum. Shandong Forestry Science and Technology 48(04): 1-5.

Allario T, Brumos J, Colmenero-Flores JM, Tadeo F, Morillon, R. 2011. Large changes in anatomy and physiology between diploid rangpur lime (Citrus limonia) and its autotetraploid are not associated with large changes in leaf gene expression. Journal of Experimental Botany 62(8):2507-2519. https://doi.org/10.1093/jxb/erq467

Allen JF, Forsberg J. 2001. Molecular recognition in thylakoid structure and function. 6(7): 0326. DOI: 10.1016/S1360-1385(01)02010-6

Arnon DI. 1949. Copper enzymes in isolated chloroplasts. Polyphenoloxidase in beta-vulgaris. Plant Physiol 24: 1-15.

DOI: $10.1104 /$ pp.24.1.1

Beale S. 2005. Green genes gleaned. Trends in Plant Science 10(7):309-312.

DOI: $10.1016 /$ j.tplants.2005.05.005

Chen YG, Chen JF, Li WG, Cui L, Chen LZ. 2010. Photosynthetic characteristics and ultrastructure in Cucumis allopolyploids with different ploid levels. Journal of Nanjing Agriculturel University 33(01):32-36. 46. Beijing: Science Press, 183. 
520 Coate JE, Schlueter JA, Whaley AM, Doyle JJ. 2014. Divergent evolutionary fates of major

521 photosynthetic gene networks following gene and whole genome duplications. Plant Signal

522 Behav 6(4):2081-2095. DOI: 10.4161/psb.6.4.15370

523

524

525

526

527

528

529

530

531

532

533

534

535

536

537

538

539

540

541

542

543

544

545

546

Coate JE, Luciano AK, Seralathan V, Minchew KJ, Owens TG, Doyle JJ. 2012.

Anatomical, biochemical, and photosynthetic responses to recent allopolyploidy in Glycine dolichocarpa (Fabaceae). American Journal of Botany 99: 55-67. DOI: 10.3732/ajb.1100465

Cock PJA, Fields CJ, Naohisa G, Heuer ML, Rice PM. 2010. The sanger fastq file format for sequences with quality scores, and the solexa/illumina fastq variants. Nucleic Acids Research 6(38):1767-1771. https://doi.org/10.1093/nar/gkp1137

Comai L. 2005. The advantages and disadvantages of being polyploid. Nature Reviews Genetics 6: 836-846. DOI: https://doi.org/10.1038/nrg1711

Conesa A, Götz S, García-Gómez JM, Terol J, Talón M, Robles M. 2005. Blast2GO:

Auniversal tool for annotation, visualization and analysis in functional genomics research. Bioinformatics 21: 3674-3676.

Dhooghe E, Laere KV, Eeckhaut T Leus L, Huylenbroeck J. 2011. Mitotic chromosome doubling of plant tissues in vitro. Plant Cell Tissue \& Organ Culture 104(3):359-373.

DOI: $10.1007 / \mathrm{s} 11240-010-9786-5$

\section{Dong B, Wang HB, Liu T, Cheng PL, Chen Y, Chen SM, Guan ZY, Fang WM, Jiang JF,}

Chen FD. 2017. Whole genome duplication enhances the photosynthetic capacity of

Chrysanthemum nankingense. Molecular Genetics and Genomics 292: 1247-1256.

DOI: $10.1007 / \mathrm{s} 00438-017-1344-y$ 
Doležel J, Greilhuber J, Suda J. 2007. Estimation of nuclear DNA content in plants using flow 549 cytometry. Nature Protocols 2(9): 2233-2244.

550 DOI: https://doi.org/10.1038/nprot.2007.310

551

552

553

554

Du L, Li YC, Mu HZ, Zhang TY, Liu FF, Huang HJ, Liu GF. 2011. Photosynthetic Characteristics of Tetraploid and Diploid Betula platyphylla. Journal of Northeast Forestry University 39 (2): 1-4. DOI:10.13759/j.cnki.dlxb.2011.02.017

555

Eckhardt U, Grimm B, Hörtensteiner S. 2004. Recent advances in chlorophyll biosynthesis and breakdown in higher plants. Plant Mol. Biol 56: 1-14. DOI: 10.1007/s11103-004-2331-3

558

559

560

561

562

563

564

565

566

567

568

569

570

571

572

28(11):306-311.

573 
574 Gao S, Yan Q, Chen L, Song Y, Li J, Fu C, Dong M. 2017. Effects of ploidy level

575 and haplotype on variation of photosynthetic traits: novel evidence from two Fragaria

576 species. PLoS One 12: e0179899. DOI: 10.1371/journal.pone.0179899

577

578

579

Grabherr MG, Haas BJ, Yassour M, Levin JZ, Thompson DA, Amit I, Adiconis X, Fan L, Raychowdhury R, Zeng Q. 2011. Full-length transcriptome assembly from RNA-Seq data

580

581

582

583

584

585

586

587

588

589

590

591

592

593

594

595

596

597

598

599

600 without a reference genome. Nat. Biotechnol 29 644-652.

DOI: https://doi.org/10.1038/nbt.1883

Greenwood AD, Leech RM, Williams JP. 1963. The osmiophilic globules of chloroplasts. I. Osmiophilic globules as a normal component of chloroplasts and their isolation and composition in Vicia faba L. Biochimica Et Biophysica Acta 78(1):148-162.

DOI: $10.1016 / 0006-3002(63) 91620-2$

Guo X, Guo WH, Luo YJ, Tan XF, Du N, Wang RQ. 2013. Morphological and biomass characteristic acclimation of trident maple (Acer buergerianum Miq.) in response to light and water stress. Acta Physiologiae Plantarum 35(4):1149-1159.

DOI: $10.1007 / \mathrm{s} 11738-012-1154-0$

Hayashi M. 2007. Tree bark handbook. Tokyo: Bun-ichi Co.Ltd.

Kanehisa M, Araki M, Goto S, Hattori M, Hirakawa M, Itoh M, Katayama T, Kawashima

S, Okuda S, Tokimatsu T. 2008. KEGG for linking genomes to life and the environment.

Nucleic Acids Res 36: D480-D484.

Kramer DM, Johnson G, Kiirats O, Edwards GE. 2004. New fluorescence parameters for the determination of QA redox state and excitation energy fluxes. Photosynth. 
601

602

603

604

605

606

607

608

609

610

611

612

613

614

615

616

617

618

619

620

621

622

623

624

625

626

627

Res 79: 209-218. DOI: 10.1023/B:PRES.0000015391.99477.0d

Kron P, Husband BC. 2012. Using flow cytometry to estimate pollen DNA content: improved methodology and applications. Ann BotLondon 110(5): 1067-1078.

DOI: $10.1093 / \mathrm{aob} / \mathrm{mcs} 167$

Leal-Bertioli SC, Moretzsohn MC, Santos SP, Brasileiro AC, Guimaraes PM, Bertioli DJ, Araujo AC. 2017. Phenotypic effects of allotetraploidization of wild Arachis and their implications for peanut domestication. American Journal of Botany 104: 379-388.

DOI: $10.3732 / a j b .1600402$

Liang HZ, Dou DQ, Feng YL. 2004. Diurnal changes in photosynthesis and chlorophyll fluorescence parameters of Amoomvilosum lour. Acta Ecologica Sinica 24(7): 1421-1429.

Li HS. 2000. Principles and techniques of plant physiological and biochemical experiments. Beijing: Higher Education Press. 134-138.

Li W, Yang S, Lu Z, He Z, Ye Y, Zhao B, Wang L, Jin B. 2018. Cytological, physiological, and transcriptomic analyses of golden leaf coloration in Ginkgo biloba L. Horticulture Research 5: 12. https://doi.org/10.1038/s41438-018-0015-4

Liu Y, Li X, Liu M, Cao B, Tan H, Wang J, Li X. 2012. Responses of three different ecotypes of reed (Phragmites communis Trin.) to their natural habitats: leaf surface micro-morphology, anatomy, chloroplast ultrastructure and physio-chemical characteristics. Plant Physiology \& Biochemistry 51: 159-167. DOI: 10.1016/j.plaphy.2011.11.002

Masuda T, Fujita Y. 2008. Regulation and evolution of chlorophyll metabolism. Photochem. 
628

629

630

631

632

633

634

635

636

637

638

639

640

641

642

643

644

645

646

647

648

649

650

651

652

653

654

Photobiol. Sci. 7: 1131-1149.

Matsumoto M, Yada M, Hatakeyama S, Ishimoto H, Tanimura T, Tsuji S, Kakizuka A,

Kitagawa M, Nakayama KI. 2004. Molecular clearance of ataxin-3 is regulated by a

mammalian E4. Embo Journal 23: 659-669.

DOI: $10.1038 /$ sj.emboj.7600081

Matsue M, Takeda Y. 2009. Technical Note of National Institute for Land and Infrastructure Management, No. 506. The Street Tree of Japan VI, National Institute for Land and

Infrastructure Management, Ministry of Land, Infrastructure, Transport, and Tourism; 76.

Ohmiya A, Hirashima M, Yagi M, Tanase K, Yamamizo C. 2014. Identification of Genes Associated with Chlorophyll Accumulation in Flower Petals. Plos One 9(12): e113738.

DOI: 10.1371/journal.pone.0113738

Otto SP. 2007. The evolutionary consequences of polyploidy. Cell 131: 452-462.

DOI: $10.1016 /$ j.cell.2007.10.022

Paul K, Husband BC. 2012. Using flow cytometry to estimate pollen DNA content: improved methodology and applications. Annals of Botany (5):1067-1078. DOI: 10.1093/aob/mcs167

\section{Pertea G, Huang X, Liang F, Antonescu V, Sultana R, Karamycheva S, Lee Y, White J,}

Cheung F, Parvizi B, Tsai J, Quackenbush J. 2003. TIGR gene indices clustering tools (TGICL): A software system for fast clustering of large EST datasets. Bioinformatics 19: 651652. DOI: $10.1093 /$ bioinformatics/btg034

Tang W, Wang W, Chen D, Ji Q, Jing Y, Wang H, Lin R. 2012. Transposase-derived proteins 
655

656

657

658

659

660

661

662

663

664

665

666

667

668

669

670

671

672

673

674

675

676

677

678

679

680

681

FHY3/FAR1 interact with phytochrome interacting factor1 to regulate chlorophyll biosynthesis

by modulating HEMB1 during deetiolation in Arabidopsis. Plant Cell

24(5): 1984-2000. https ://doi.org/10.1105/tpc.112.09702 2

\section{Van Laere K, Franca SC, Vansteenkiste H, Van Huylenbroeck J, Steppe K, Van Labeke}

MC. 2010. Influence of ploidy level on morphology, growth and drought susceptibility in

Spathiphyllum wallisii. Acta Physiologiae Plantarum 33(4):1149-1156.

DOI: $10.1007 / \mathrm{s} 11738-010-0643-2$

Wang BS, Han JF, Wang YL, Sui DZ. 2006. A preliminary study on the seedling stage test of several garden maples. Journal of Jiangsu Forestry Science \& Technology 34 (1): 10-14.

Wang L, Feng Z, Wang X, Wang X, Zhang X. 2010. Degseq: an R package for identifying differentially expressed genes from rna-seq data. Bioinformatics 26(1):136-138.

https://doi.org/10.1093/bioinformatics/btp612

Wang Y, Zhang XS, Deng MJ, Zhao ZL, Fan GQ. 2013. Study on Photosynthetic Characteristics of Diploid and Tetraploid Paulownia australis. Acta Agriculturae Jiangxi 25(08): 39-42+45.

Wang Z. 2000. Plant Physiology. Beijing: China Agriculture Press. 125-128.

Warner DA, Edwards GE. 1993. Effects of polyploidy on photosynthesis. Photosynth Research 35: 135-147. DOI: 10.1007/BF00014744

Xu Y. 1998. The Systematic Evolution and Distribution of the Genus Acer. ACTA BOTANICA YUNNANICA 20(4):383-393. 
683 Yamori W, Shikanai T. 2016. Physiological functions of cyclic electron transport around 684 photosystem I in sustaining photosynthesis and plant growth. Annual review of plant biology 67: 685 81-106.

686 DOI: 10.1146/annurev-arplant-043015-112002

687

Zhang F, Hu HQ, Wang LH, Zhou Q, Huang XH. 2018. Effects of rare earth and acid rain pollution on plant chloroplast ATP synthase and element contents at different growth stages. Chemosphere Oxford 194: 441-449. DOI: 10.1016/j.chemosphere.2017.12.001

691

Zhang JE, Guo WW, Deng XX. 2006. Relationship between ploidy variation of citrus calli and 693 competence for somatic embryogenesis. Acta Genet. Sin. 33: 647-654.

DOI: $10.1016 / \mathrm{S} 0379-4172(06) 60095-4$

695

Zhu HJ, Liu WG, Zhao SJ, Yan ZH, Lu XQ, He N, Yuan PL, Guan LY. 2012. Leaf Ultrastructure Comparison of Watermelon Seedling with Different Ploidy. China Cucurbits and Vegetables 25(03): 5-7. DOI: 10.16861/j.cnki.zggc.2012.03.002

699

Zhang YB, Chen JF, Yi HP, Feng JX, Wu MZ. 2005. Staining and Slide-preparing Technique of Mitotic Chromosomesand Its Use in Karyotype Determination of Cucumis melo L. Acta Botanica Boreali-Occidentalia Sinica (09): 1735-1739. 


\section{Table 1 (on next page)}

Maximum gas exchange parameters of different ploidies

It contains the maximum values of $T_{\mathrm{r},}, P_{\mathrm{n}}, \mathrm{C}_{\mathrm{i}}, G_{\mathrm{s}}$ from May to September. 


\begin{tabular}{|c|c|c|c|c|c|}
\hline Month & Ploidy & $\begin{array}{c}\text { Maximum net } \\
\text { photosynthetic rate } \\
\left(P_{\mathrm{n} \max }, \mu \mathrm{mol} \cdot \mathrm{m}^{-2} \cdot \mathrm{s}^{-}\right. \\
\left.{ }^{1}\right)\end{array}$ & $\begin{array}{l}\text { Maximum stomatal } \\
\text { conductance }\left(G_{\mathrm{s} \max },\right. \\
\left.\quad \mathrm{mol} \cdot \mathrm{m}^{-2} \cdot \mathrm{s}^{-1}\right)\end{array}$ & $\begin{array}{c}\text { Maximum } \mathrm{CO}_{2} \\
\text { concentration }\left(C_{\mathrm{i} \max },\right. \\
\left.\mu \mathrm{mol} \cdot \mathrm{mol}^{-1}\right)\end{array}$ & $\begin{array}{c}\text { Maximum } \\
\text { transpiration rate } \\
\left(T_{\mathrm{r} \max }, \mathrm{mol} \cdot \mathrm{m}^{-2} \cdot \mathrm{s}^{-1}\right)\end{array}$ \\
\hline \multirow{3}{*}{ May } & Tetraploid X & $5.3227 \pm 0.116 \mathrm{a}$ & $0.1192 \pm 0.010 \mathrm{a}$ & $309.7800 \pm 5.34 \mathrm{a}$ & $1.1123 \pm 0.128$ \\
\hline & & & & & \\
\hline & Diploid S & $5.1029 \pm 0.020 \mathrm{~b}$ & $0.0864 \pm 0.004 b$ & $293.4500 \pm 3.83 b$ & $0.9872 \pm 0.036$ \\
\hline \multirow{3}{*}{ June } & Tetraploid X & $5.9249 \pm 0.153 \mathrm{a}$ & $0.1174 \pm 0.008 \mathrm{a}$ & $351.7200 \pm 3.112 \mathrm{a}$ & $1.2764 \pm 0.230$ \\
\hline & & & & & \\
\hline & Diploid S & $5.2735 \pm 0.030 \mathrm{~b}$ & $0.0828 \pm 0.000 \mathrm{~b}$ & $301.0400 \pm 16.64 \mathrm{~b}$ & $1.0885 \pm 0.046$ \\
\hline \multirow{2}{*}{ July } & Tetraploid X & $8.4846 \pm 0.179 a$ & $0.1123 \pm 0.006 \mathrm{a}$ & $355.2300 \pm 8.338 \mathrm{a}$ & $1.3319 \pm 0.110$ \\
\hline & Diploid S & $7.8211 \pm 0.029 b$ & $0.0907 \pm 0.000 \mathrm{~b}$ & $301.0400 \pm 16.64 b$ & $1.2282 \pm 0.006$ \\
\hline \multirow{3}{*}{ August } & Tetraploid X & $11.1538 \pm 0.455 \mathrm{a}$ & $0.1900 \pm 0.143 a$ & $335.2800 \pm 2.656 \mathrm{a}$ & $1.1238 \pm 0.048$ \\
\hline & & & & & \\
\hline & Diploid S & $8.5592 \pm 0.024 b$ & $0.1454 \pm 0.005 b$ & $301.4300 \pm 10.334 \mathrm{~b}$ & $0.8357 \pm 0.011$ \\
\hline \multirow{3}{*}{ September } & Tetraploid X & $9.1703 \pm 0.180 \mathrm{a}$ & $0.1448 \pm 0.006 \mathrm{a}$ & $323.5100 \pm 6.417 \mathrm{a}$ & $1.2562 \pm 0.030$ \\
\hline & & & & & \\
\hline & Diploid S & $8.5103 \pm 0.032 b$ & $0.1189 \pm 0.004 b$ & $294.5100 \pm 11.461 \mathrm{~b}$ & $0.9756 \pm 0.014$ \\
\hline
\end{tabular}

4

5 Values represent the mean \pm standard error (SE) of at least three tagged in dividuals of each ploidy type.

6 Different lowercase letters within a row indicate statistically significant differences $(\mathrm{P}<0.01)$ between the two ploidy level on

7 the same day. The same letters mean the difference is not significant, and the different letters mean the difference is significant. 
Table 2 (on next page)

Differentially expressed genes in the chlorophyll synthesis pathway

It contains information about genename,geneID, and size. 
Table 2. Differentially expressed genes in the chlorophyll synthesis pathway

\begin{tabular}{|c|c|c|c|}
\hline Gene name & Gene ID & Size (bp) & $\log 2(\mathrm{X} / \mathrm{S})$ \\
\hline \multirow{5}{*}{ HemB } & CL3197.Contig1 & 1743 & 1.2136 \\
\hline & CL3197.Contig2 & 1848 & 4.9716 \\
\hline & CL3197.Contig3 & 1474 & 1.8448 \\
\hline & CL3197.Contig4 & 1213 & 7.4426 \\
\hline & CL3197.Contig5 & 1343 & 7.2818 \\
\hline HemC & CL3343.Contig1 & 1446 & -1.8068 \\
\hline HemE & CL633.Contig2 & 1641 & -1.0693 \\
\hline \multirow{3}{*}{$\mathrm{CHLH} / \mathrm{D} / \mathrm{I}$} & CL6001.Contig1 & 2592 & -1.6240 \\
\hline & CL6001.Contig2 & 2776 & 3.7295 \\
\hline & Unigene11625 & 2263 & -1.1987 \\
\hline
\end{tabular}

2 


\section{Figure 1}

Chlorophyll contents and chlorophyll fluorescence parameters in X and S

The leaf chlorophyll a/b content and chlorophyll fluorescence parameters in X and S. Asterisk mean values for the $X$ and $S$ differ signifcantly according to ANOVA $(p<0.05)$. 


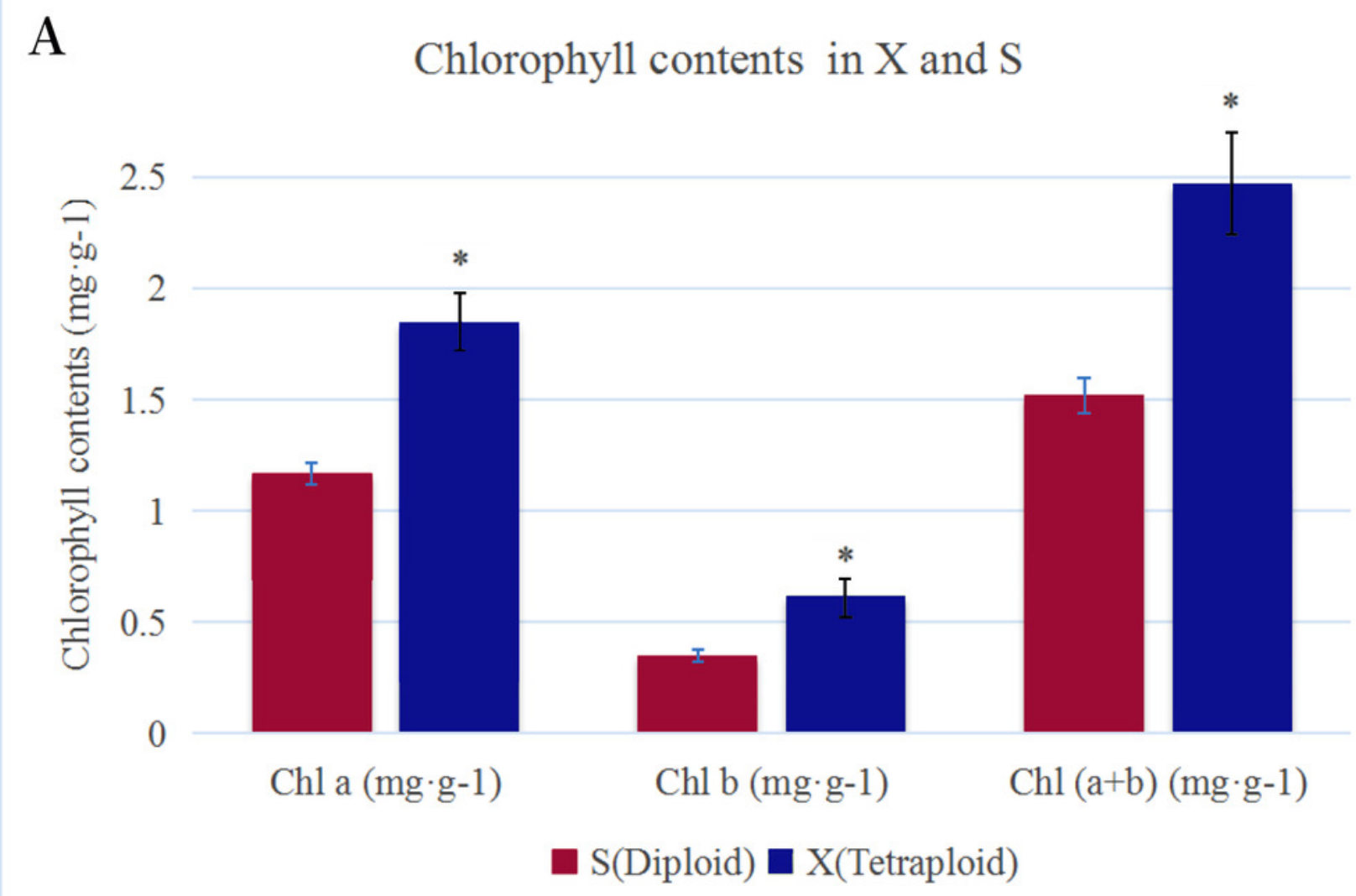

B

Chlorophyll fluorescence parameters in $\mathrm{X}$ and $\mathrm{S}$

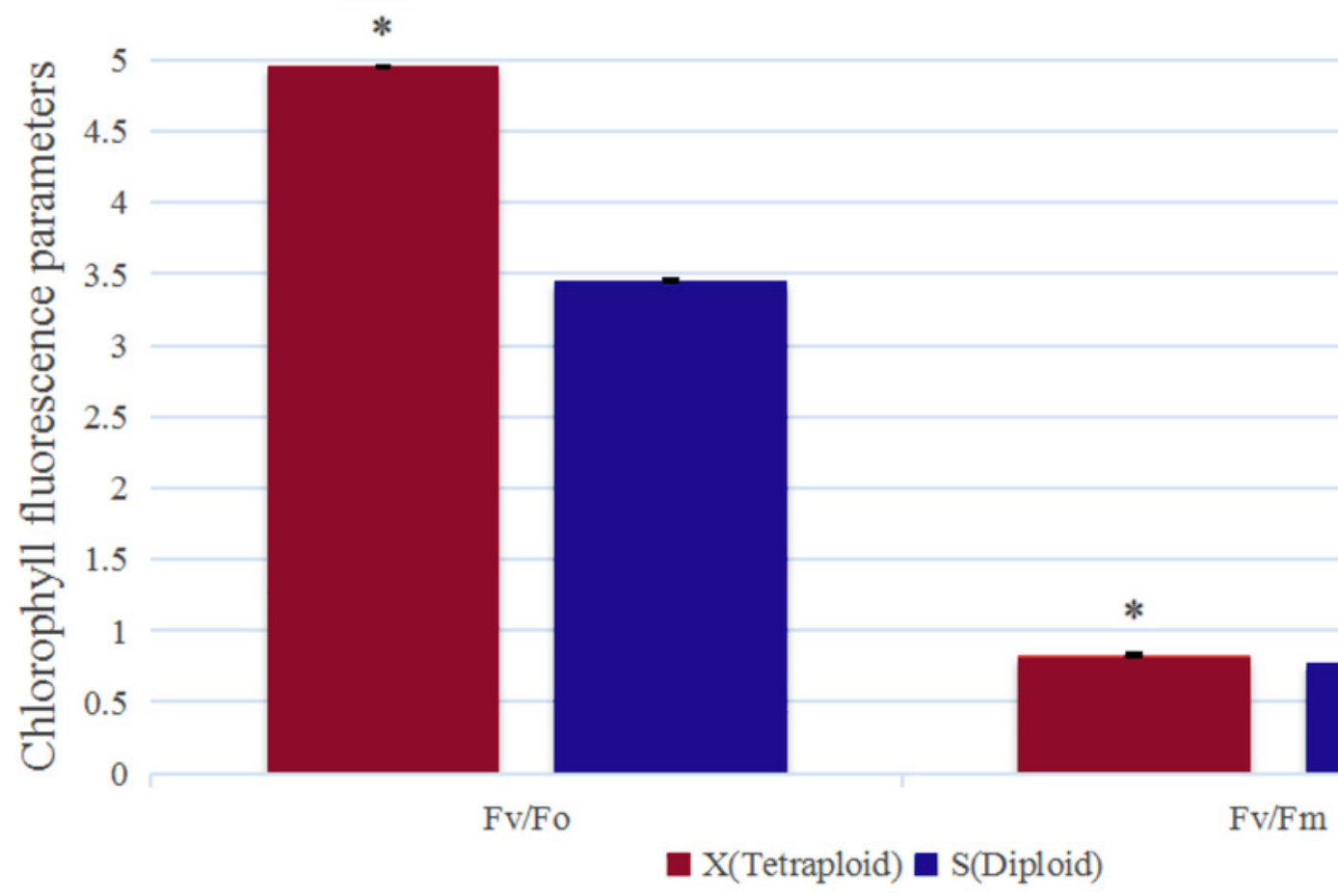


Figure 2

Ultrastructure of the mesophyll cell chloroplasts

A and a: A. buergerianum diploid; B and b: A. buergerianum tetraploid. Ch: chloroplast; SG:

starch grains; G: grana; O: plastoglobuli. 


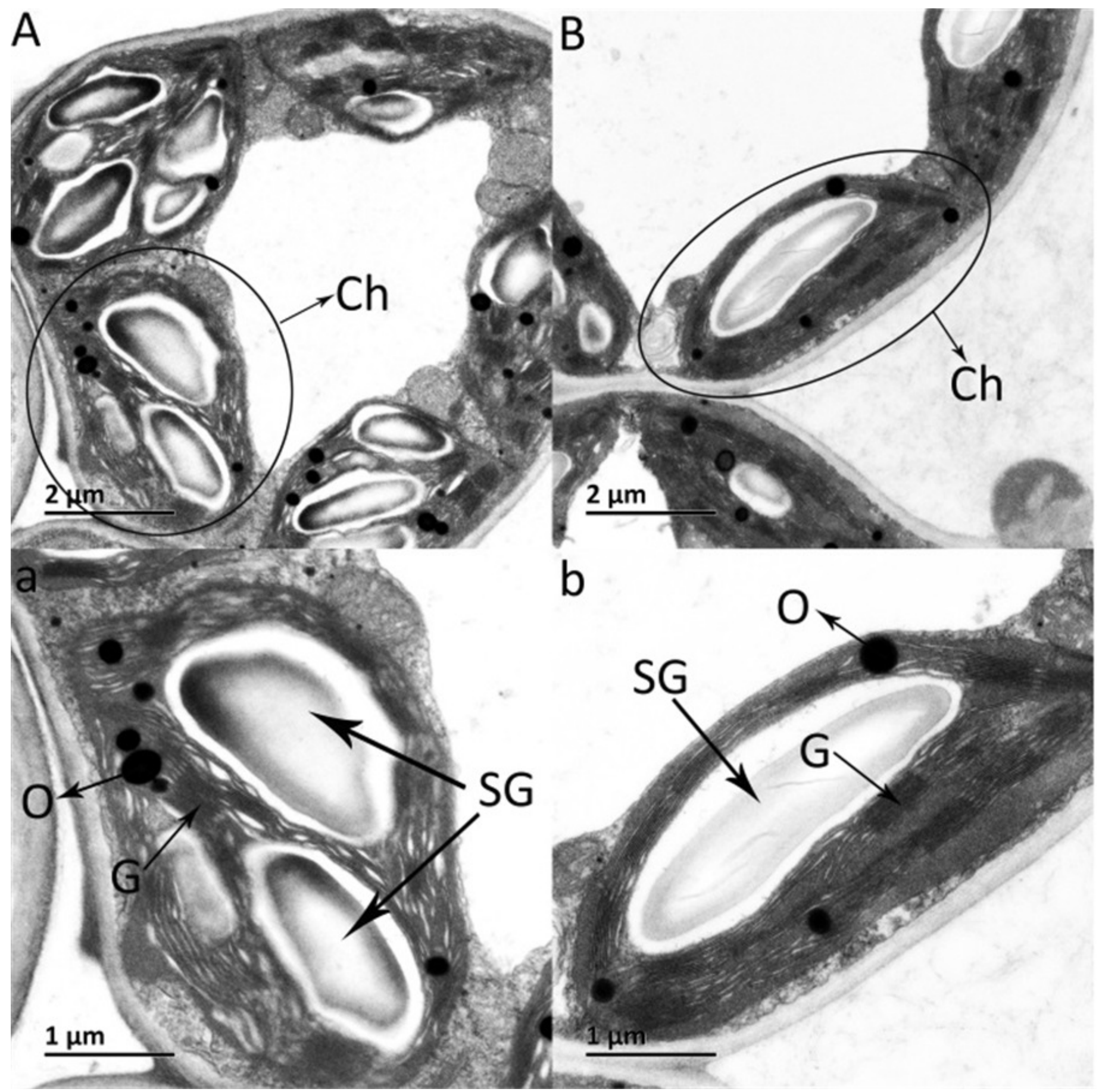


Figure 3

Comparison of thylakoid lamella thickness and plastoglobuli number of $\mathrm{X}$ and $\mathrm{S}$

Asterisk mean values for the $X$ and $S$ differ signifcantly according to ANOVA $(p<0.05)$. 
A

Comparison of thylakoid lamella thickness of X and S

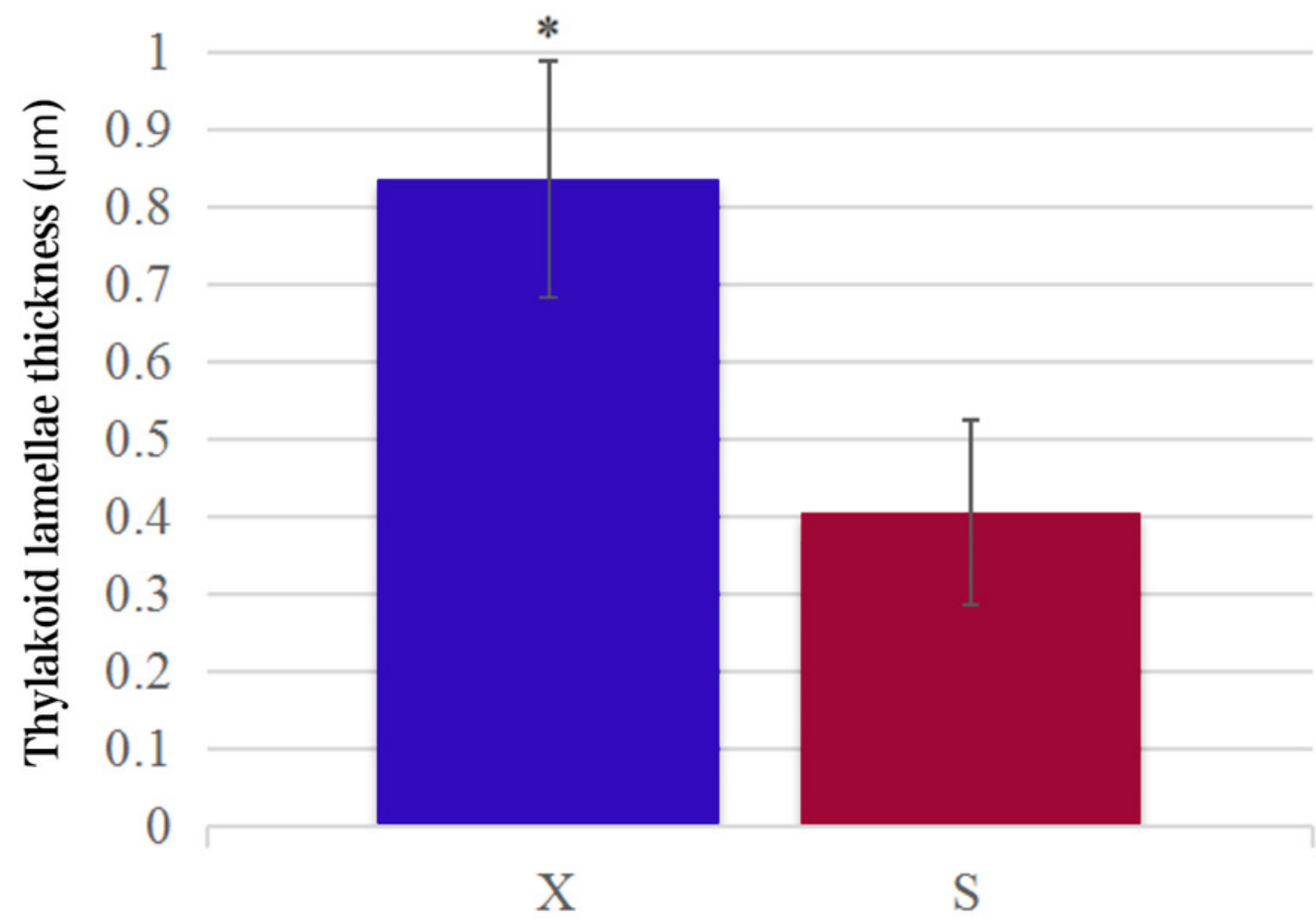

B

Comparison of Plastoglobuli number of $\mathrm{X}$ and $\mathrm{S}$

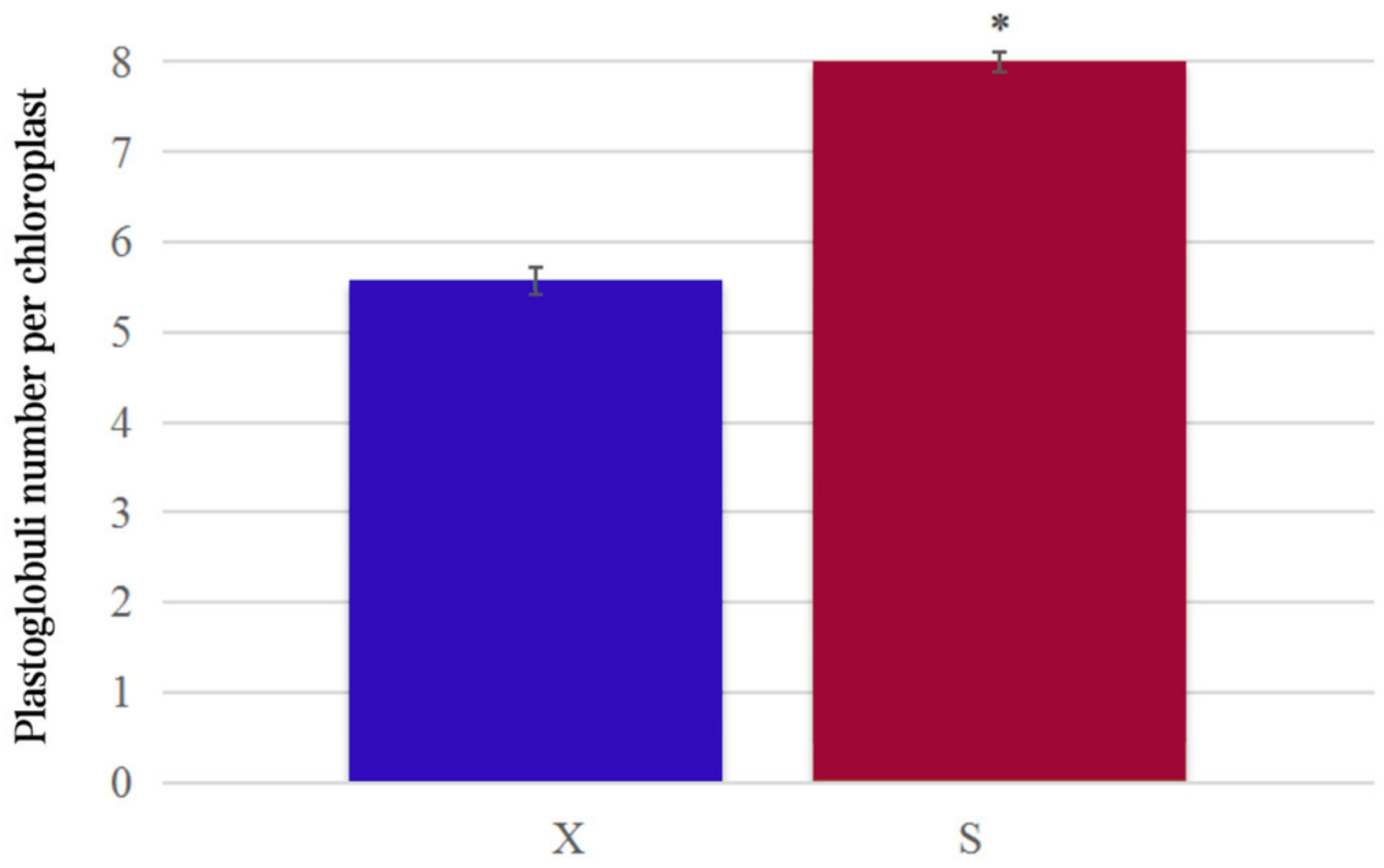


Figure 4

Photosynthesis pathway

Up-regulated genes in $A$. buergerianum $\mathrm{X}$ are represented by purple boxes, and downregulated genes are represented by blue boxes.
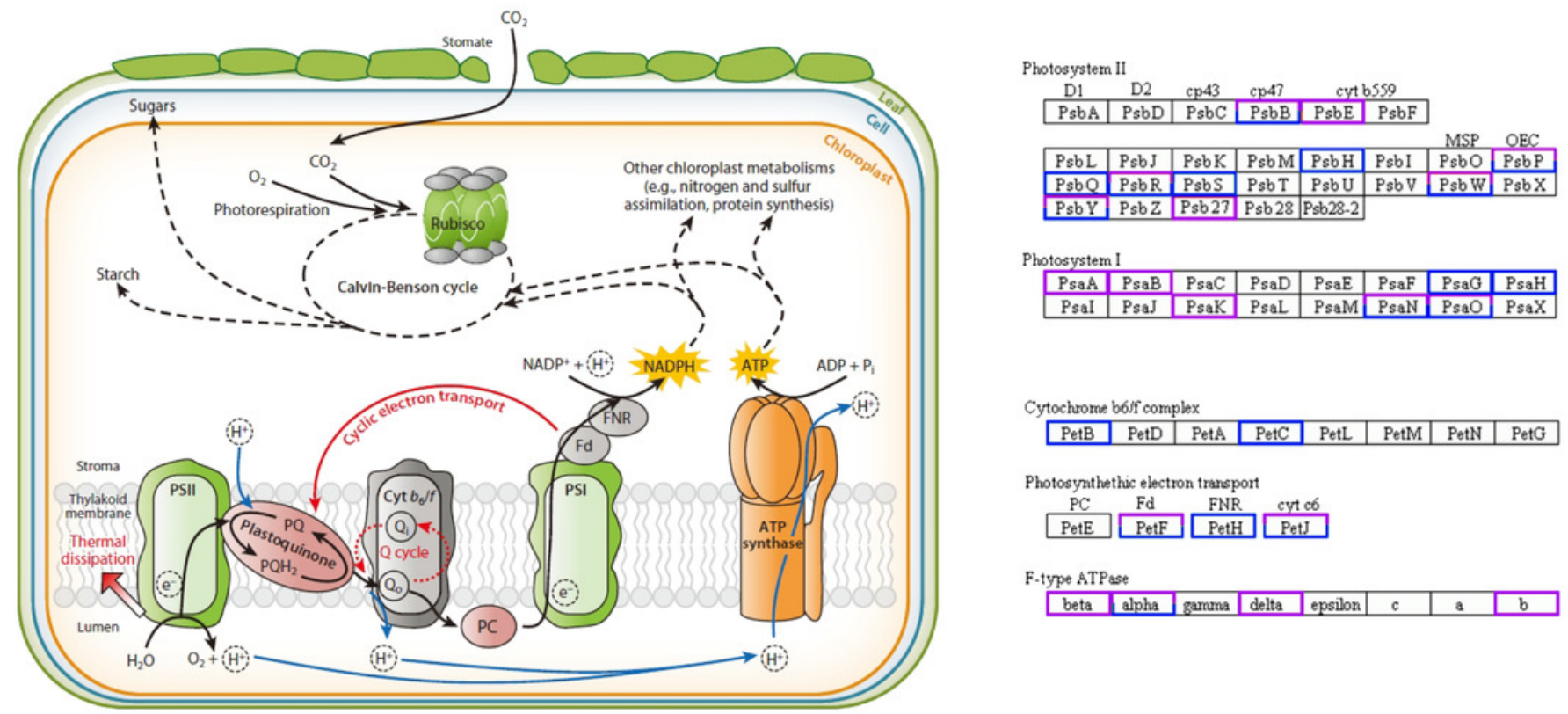

Photosystem I

\begin{tabular}{|l|l|l|l|l|l|l|l|}
\hline PsaA & PsaB & PsaC & PsaD & PsaE & PsaF & PsaG & PsaH \\
\hline
\end{tabular}

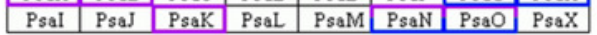

Cytochrome b6if complex

\begin{tabular}{|l|c|c|c|c|c|c|c|}
\hline PetB & PetD & PetA & PetC & PetL & PetM & PetN & PetG \\
\hline
\end{tabular}

Photosynthethic electron transport

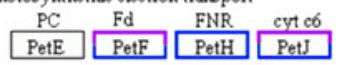

F-type ATPase

\begin{tabular}{|l|l|l|l|l|l|l|l|}
\hline beta & alpha & gamma & delta & epsilon & c & a & b \\
\hline
\end{tabular} 
Figure 5

Schematic diagram for the possible mechanisms for the increased photosynthetic capacity of $X$

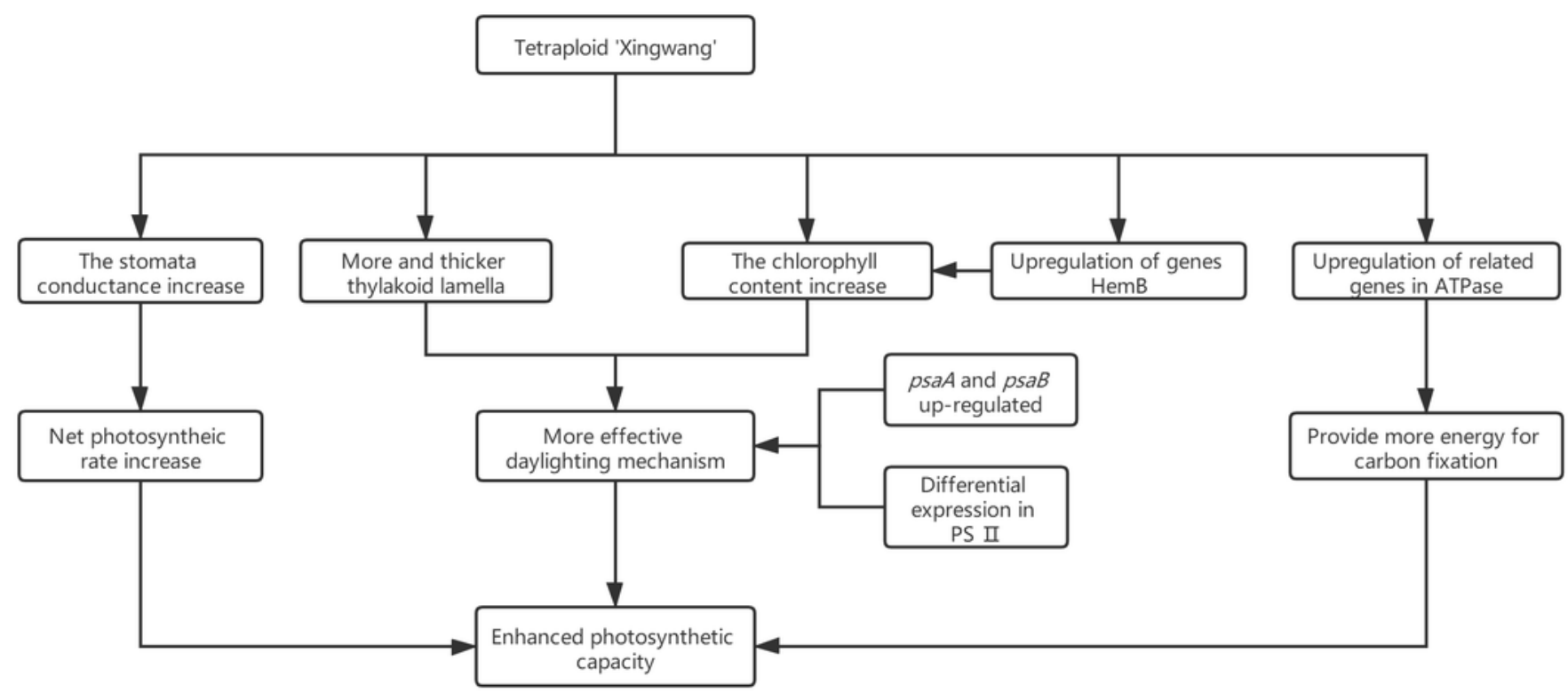

